\title{
Perspectives of building professionals on the use of LCA tools in Swedish climate declaration
}

\author{
Gireesh Nair $^{1 *}$, Ake Fransson ${ }^{1}$, and Thomas Olofsson ${ }^{1}$ \\ ${ }^{1}$ Department of Applied Physics and Electronics, Umeå University, Sweden
}

\begin{abstract}
From $1^{\text {st }}$ January 2022, Swedish government plan to introduce the climate declarations as a legal requirement for new buildings. LCA is a method that could be used to quantify buildings' climate impact. The climate declaration in the Swedish building code expects to create interest in LCA among stakeholders. This study aims to identify and understand the challenges and opportunities of using LCA by stakeholders during the early stage of construction process. The study is based on responses from six building professionals to a questionnaire. The policy implications of the study findings are discussed.
\end{abstract}

\section{Introduction}

The building and real estate sector account for approximately $40 \%$ of final energy use in Sweden [1], and also causes $19 \%$ of domestic GHG emissions from a life cycle perspective [2]. In 2017 Swedish government has adopted a climate policy frame work which stipulates the country to have net zero greenhouse gas (GHG) emissions by 2045 [3]. The building sector has an important role in achieving Sweden's climate goal. Choices made in the design stage of buildings often have significant environmental impact over its life cycle. It is required to carefully design a building in such a manner that it uses as low energy as possible and emit minimum GHG emissions as possible, over its life cycle. Sweden has undertaken several initiatives to steer the buildings to be more energy efficient and climate friendly.

Climate declaration of buildings is a new initiative aimed to reduce the climate impact of buildings and also to raise knowledge on the topic. From 1st January 2022 onwards, the climate impact of new buildings should be reported in the climate declaration. An important step in climate declaration is to use LCA method for identifying and quantifying the buildings' climate impact [3]. LCA as a tool to study the life cycle environmental impact has been around for the last several decades [4]. Climate declaration is expected to result in widespread use of LCA tools in building sector in Sweden.

In this study, we analyzed the perspectives of practicing professionals on climate declaration and concerns related to use of LCA tools.

\section{Climate declaration and LCA tools}

The Swedish National Board of Housing, Building and Planning (Boverket) has been entrusted with the task to propose a plan for the further development of the regulations on climate declarations. Currently it is not planned to have the limit values GHG emissions from buildings in the first phase of climate declaration from 2022-2026, while it is proposed to introduce limit values for climate emissions from the construction stages (modules A1-A5 as per SS-EN 15978) of buildings from 2027 and gradually decreasing it till 2043 [5]. Limit values are the conditions needed to achieve the 2045 zero-emission target. Boverket plans to develop an open database with relevant climate data that can be used to calculate the climate impact from buildings from a life cycle perspective [2].

LCA is a method that could be used to quantify buildings' climate impact. The information from LCA analysis could guide the decision makers, such as the clients/building owners, to make choices of the components/techniques/process that could reduce the environmental impact such as greenhouse gas emission. Nevertheless, several barriers are reported in the use of LCA, especially in the building sector, including perceived complexities, accuracy in results, high cost involved in performing an LCA [6]. LCAs are currently done after the project completion [7] which limits the usefulness of the study in terms of possible interventions to reduce the environmental impact. It is reported that practitioners are facing uncertainty and variations in results when using LCA [8].

Other reasons that may hinder the use of LCA by the industry is the lack of integration of LCA in routine building related tools and lack of LCA expertise. Conducting LCA especially at the building design stage is reported as time consuming [9]. The need of reliable simplifications in the application of LCA methods in buildings has been recognized by several studies and some LCA method were suggested with a simplified approach [10]. However, a simplified LCA could have an implication on the reliability of the results. This field can be improved by conducting further analysis with a more data driven approach.

* Corresponding author: gireesh.nair@umu.se 
Further, the data used in LCA have a significant effect on its results [11] and thereby could lead to challenges in establishing whether the building is able to meet the climate impact requirement. An issue in the early stage of design is the non-availability of detailed information of the products since usually contractors do not have all information on the products until the construction process begin. The availability of product data for design phase in LCA analysis seems to be limited [12]. Therefore, generic data for environmental impacts must be used, which is generalized conventional data for a product. Generic data is usually based on historical mean data for similar products, and therefore is not the exact environmental impact for a specific product. A building is constructed with several different products and many of those products are available in different qualities and types the choice of generic data when performing an LCA could be challenging. Takno et al [11] provides a starting point on the selection of an LCA database for the construction materials. Their study is based on few databases from Europe and US. Their analysis covers a few specific territories and conclude that the objectives of the user determines the appropriate database. As per a review by Säynäjoki et al [13], in most cases, the methodological issues and subjective choices of the LCA practitioner are the cause for large variance in the results.

\section{Methodology}

This study is part of a large project aimed to find ways to build climate neutral residential buildings in a new neighbourhood planned in the city of Umeå, Sweden. One of the activities to achieve this objective is to gather information from practitioners representing important stakeholders from the region. Accordingly, discussion was carried out with Umeå municipality representative, who has the mandate to develop the new neighbourhood, to identify reference group members. Six members for the reference group who work in six different organizations was identified: two members in the reference group work in building and city development consultancy organizations, two works in building companies, one member is working in a municipality, and the sixth member is from a company that develops residential and public properties. All the participants have extensive experience in sustainable building construction. As a first step in the project an open-ended questionnaire was sent to reference group members. This was followed up with two online reference group meetings. The questionnaire includes questions on respondents' views on LCAs, climate declaration and specific questions on achieving the climate neutrality for the planned neighbourhood in Umeå. This paper presents the responses of reference group members to the questionnaire on use of LCA tools and climate declaration.

\section{Survey results}

\subsection{Perspectives on climate declaration}

The perspectives on the new climate declaration was collected by the question: "Do you/your company see climate declarations as a useful tool that can significantly reduce GHG emissions in new buildings?"

All the respondents believe that climate declaration could help in reducing the GHG emissions from the buildings. As per the respondent who work with the municipality, at some point it is important to have information on the environmental impacts due to building construction and climate declaration could be useful in this aspect. Nevertheless, he is uncertain on how much time it would take for the climate declaration to influence reduction in environmental burden associated with building construction. Both personnel from the consultancy organization believe that climate declaration is a useful tool to reduce the GHG emissions from buildings. According to one of them, even though the climate declaration requirement will commence from 2022 onwards, people are already making demands on it. Further, she believes that even though the planned law does not contain a limit on GHG emissions requirement, there will be requirements on GHG emission limits in future procurements. For example, clients may make demands that go beyond the legal requirement and/or evaluates tenders with $\mathrm{CO}_{2}$ as a parameter. As per another respondent the climate declaration will force large number of people and organizations to work on this topic and when many people work with these then new creative solutions to reduce the climate impact will emerge. According to a respondent working in a building company the climate declaration could increase the knowledge on climate issues associated with building sector. However, it should not be the sole criteria for construction decision as then there is a risk for suboptimization of possibilities to reduce the environmental impact.

The representative from the municipality and the housing development organization mentioned that they do not have internal competence and capacity to carry out the upcoming requirements for climate declaration. A few respondents believe that climate declaration need to be supplemented with more information and/requirements. For example, one of the respondents mentioned that it needs to have information on "what should be included and not and how values should be verified and compared".

\subsection{Perspectives on use of LCA in climate declaration}

Organizations use different LCA software such as Simapro, Gabi, One-Click-LCA, Anavitor and Bidcon Climate module. The building consultant pointed out that it took 30 hours less for them to make a climate declaration for a $60,000 \mathrm{~m}^{2}$ office building from the BIM model than from a manual quantity list. 


\subsubsection{Preference for a specific tool for calculations in} climate declaration

As per the respondent from Umeå municipality, it is important to have some sort of standards for the LCA tools as without which the results could differ based on the LCA software used for life cycle assessment. Similarly, one of the professional from the consultancy organization would like to have an LCA software that use quality assured data base and calculation methods and system boundaries. This according to him could provide a fair and comparable results when organizations use different LCA tools. The other consultancy professional think that it may not be good idea to recommend a specific tool and instead the choice should be kept open so as to use the tool that provides the greatest opportunity to improve the project. The respondents from the building company think that one should not be locked-in with a specific tool while the other building company professional think that it is not the tool but the quality of the input data that matters. The representative from housing development organization stated that an LCA tool should be adapted for calculation of wooden frame and modular industrial construction.

\subsubsection{Major challenges in using LCA for decision- making in the initial stages of the building design}

As per the representative from the consultancy organization the real challenge to use LCA for decision making is the lack of competency. According to her, even if the organizations gets external help for LCA it is difficult to assess the competency of the organizations hired for doing LCA studies. Further, she mentioned that this field is complex and so finding someone who "knows the tool" is not enough as one need to understand the entire method that is built into the tools. Otherwise the results could be interpreted wrongly. If the procurement systems may require the calculations comparable, for example, if the results are to be assessed at a tendering stage then it may require that climate impact results from companies that use different LCA tools need to be legally valid. It may not be possible to have much "freedom" in the calculations if results from different tools should be comparable. She mentioned that it is important to have proper procedures. However, if the procedures are formulated too detailed then it may cause suboptimization of solutions.

The municipality representative mentioned that they do not have knowledge on how to use LCA tools. He stated that building construction companies have different levels of knowledge on LCA and how to proceed on with the information. A client may have to hire another consultant to handle project's LCA. The building developer mentioned an anecdote wherein she heard from those who worked with similar tools for several years that they still found it difficult to compare the "climate performance" of different projects. As per the representative from the housing development organization, the comparability between construction projects that use different frame materials (for example, wood framed construction and new concrete that has lower carbon foot print than conventional concrete) could be a problem with the LCA tools. According to the professional from the building company the industry may face problems as they will need to use new materials and construction methods wherein they do not have much experience with. For example, according to her, the work with climate-adapted concrete means greater challenges than before with dehydration which can be difficult to predict as it would be weather-dependent. As a suggestion she mentioned about the possibilities to have more flexible and open (provide a range for limiting values on emissions) for building permits. For example, if one is going to increase the degree of recycling and reuse in the buildings then it may cause difficulties in the planning and design. This is because of the possible uncertainty on availability of suitable materials to meet the reuse/recycling objectives once production starts. This in-turn may delay the project. According to her, reuse and recycling of materials may therefore require more flexible decision-making processes.

The consultancy company representative mentioned that LCA thinking does not really fit in to real estate companies as they are driven by financial return on their investment. According to him, use of LCA makes the project more complex for the municipalities. Further, due to several other priorities in a project the LCA can be unintentionally given low priority.

\subsubsection{Support needed to facilitate the use of LCA as a decision-making tool}

Personnel from municipality would like to have the whole process simpler, such as it should be easy to get relevant values to use in the calculation, the answers need be interpreted easily and finally it should be possible to verify the results as otherwise mistrust could arise between the results produced by different tools used for calculations. The consultancy professional mentioned that it is important that LCA becomes part of building regulations as then only it will be widely used and thereby could make a change in existing building construction. The professional from the building company referred to increase the knowledge and understanding of how LCA can be used in different stages of building construction. The importance of providing the education for small and medium-sized companies who have resource constraints was highlighted by the consultancy professional. It was opinionated by the other building professional that it is important to have a robust, flexible process that does not require a lot of manual work, rather use the existing digital tools for the input data. Further, she mentioned to introduce a role for LCA coordinators at least in the initial phases of the climate declaration. This may help the industries till the process become a routine for them.

\section{Discussion}

All survey respondents believe that climate declaration will facilitate in reducing the climate impact from buildings. Different organizations use different 
LCA tools to calculate the environmental impact of buildings. The respondents do not think that it is advisable to recommend a specific tool for LCA analysis in climate declaration. Instead according to them the quality of input data such as the database has to be given importance. One of the major challenges identified by the respondents are insufficient competency in using LCA tools. Several energy and building engineering programs in Swedish universities offer LCA courses. Nevertheless, the lack of competency concern highlighted by practising professionals may be further investigated. It may be required to train building professionals and relevant personnel in government organizations such as building permit officers in municipalities to use LCA tools. Such training program may be custom-made based on the roles of the target groups. Another concern raised is on the procurement systems, if it gives weightage to climate impact values provided by LCA tools then its legal validity needs to be ensured to have fair comparisons of the LCA results by companies who may use different LCA tools. The respondent from municipality would like the whole process of climate declaration simpler. Though it is a valid concern, efforts to make it simpler, should not undermine the quality of the results and the climate declaration objective. All stakeholders should be encouraged to use existing digital tools to prepare and analyse the climate declaration.

\section{Conclusions}

Climate declaration, a new policy tool that will be introduced in Sweden, is aimed to increase the knowledge on climate impact from buildings and also to facilitate future buildings environmentally friendlier. The climate declaration is planned in phases wherein limit values on climate emission will be introduced gradually. This paper presents views reported by building professionals on use of LCA tools in climate declaration. As per the views of the survey respondents, it is important to build competency among organizations especially small and medium companies on climate declaration. Further, it is important to ensure comparability of results used in different LCA tools. The initial few years, after climate declaration is implemented, is expected to provide significant learning experience and knowledge on various aspects related to the process which could help to fine-tune the climate declaration to achieve its objectives. The study is based on a small sample of respondents which limits the generalizability of its results. Studies involving large sample sizes are needed to investigate whether the opinions reported in this paper are widespread.

\section{Acknowledgments}

The authors gratefully acknowledge the financial support from Interreg Botnia-Atlantica project Circular Economy - A Game Changer for the Wood Building Industry, and Interreg Nord project Enhanced Sustainability of Built Environment by Collaboration and Digitalization.

\section{References}

[1] Swedish Energy Agency, 2020. Energiläget 2020. ISBN (pdf) 978-91-89184-52-7.

[2] Boverket, 2020. Tidplan för insatser och åtgärder inför krav på klimatdeklarationer: Uppförande av byggnader. Rapportnummer: 2020:3, ISBN: 978-91-7563-681-8.

[3] Regeringen, 2017. Det klimatpolitiska ramverket [Accessed from Det klimatpolitiska ramverket - Regeringen.se]

[4] Buyle, M., Braet, J., Audenaert, A., 2013. Life cycle assessment in the construction sector: A review. Renewable and Sustainable Energy Reviews 26, 379-388.

[5] Boverket, 2020. Regulation on climate declarations for buildings: proposal for a roadmap and limit values. Report number: 2020:28, ISBN: 978-91-7563-731-0.

[6] Malmqvist, T., Glaumann, M., Scarpellini, S., Zabalza, I., Aranda, A., Llera, E., Díaz, S., 2011. Life cycle assessment in buildings: The ENSLIC simplified method and guidelines, 2011. Energy 36, 1900-1907.

[7] Schlegl, F., Gantner, J., Traunspurger, R., Albrecht, S., Leistner, P., 2019. LCA of buildings in Germany: Proposal for a future benchmark based on existing databases. Energy and Buildings 194, 342-350.

[8] Pannier, M-A., Schalbart, P., Peuportier, B., 2018. Comprehensive assessment of sensitivity analysis methods for the identification of influential factors in building life cycle assessment. Journal of cleaner production, 466480.

[9] Basbagill, J., Flager, F., Lepech, M., Fischer, M., 2013. Application of life-cycle assessment to early stage building design for reduced embodied environmental impacts. Building and Environment 60, 81-92.

[10] Soust-Verdaguer, B., Llatas, C., GarcíaMartínez, A., 2016. Simplification in life cycle assessment of single-family houses: A review of recent developments. Building and Environment 103, 215-227.

[11] Takano, A., Winter, S., Hughes, M., Linkosalmi, L., 2014. Comparison of lifecycle assessment databases: a case study on building assessment. Building and Environment 79:20-30.

[12] Moreno, P.R., Rohmer, S., Ma, H-W., 2015. Analysis of potential relationships between functional analysis and life cycle assessment. Procedia CIRP 29, 390-5.

[13] Säynäjoki, A., Heinonen, J., Junnila, S., Horvath, A., 2017. Can life-cycle assessment produce reliable policy guidelines in the building sector? Environmental Research letters 12. 